Psychology of Language and Communication 2013, Vol. 17, No. 3

VERSITAOPEN

DOI: $10.2478 /$ plc-2013-0015

\author{
DACIAN DORIN DOLEAN \\ Babes Bolyai University, Cluj-Napoca
}

\title{
THE RELATIONSHIP BETWEEN PITCH DISCRIMINATION AND ROMANIAN STUDENTS’ SPELLING PERFORMANCE
}

\begin{abstract}
Previous studies have shown that music can have a positive impact on phonological awareness and on foreign language acquisition. The present research investigates specifically the role of pitch discrimination ability in native and foreign language spelling performance. Two groups of elementary school children were selected based on their pitch discrimination abilities (high and low). Their spelling performance in their native and a foreign (fictional) language was assessed. The results indicate that pitch discrimination ability can be linked to spelling ability in both the native and a foreign language. They also suggest that studying a musical instrument might predict enhanced spelling performance ability.
\end{abstract}

Key words: foreign language, music, spelling, phonological awareness, second language acquisition

\section{Introduction}

Music can have a powerful impact on brain anatomy and cognitive ability. Studies have shown that long-term piano training in children induces regionally specific effects on white matter development (Bengtsson et al., 2005), that instrumental music training in children can develop the size of the corpus callosum after 29 months of training (Schlaug et al., 2009), that children's cortical eventrelated potentials (ERPs) can change after 8 weeks of musical training (Moreno $\&$ Besson, 2006) or that preschoolers' brain activity produced EEG frequencies associated with increased cognitive processing after 7 weeks of musical training, compared with the control group (Flohr et al., 2000).

One of the cognitive abilities that has been shown to be influenced by musical ability is phonological awareness (e.g. Lamb \& Gregory, 1993; Forgeard et al.,

Address for correspondence: Dacian Dorin Dolean, Faculty of Psychology and Educational Sciences, Babes Bolyai University, Str. Sindicatelor nr. 7, Cluj-Napoca, 400029, Romania. E-mail: darisclub@gmail.com 
2008). Existing studies suggest that the cognitive processes of music production and segmentation of a spoken word into phonemes are similar. Phonological awareness can be enhanced not only by musical aptitude, but also by developed musical ability. Even when participants were not selected based on their musical aptitudes, when they received music instruction they showed enhancements in phoneme segmentation fluency (Gromko, 2005), in the development of prosodic processing (Magne, Schon \& Besson, 2006) and in reading and pitch discrimination abilities in speech (Moreno et al., 2009).

Since phonological awareness can be a good predictor for the success of native language reading and spelling abilities (Ball \& Blachman, 1991; Ehri et al., 2001; Stuart, 1999; Verhagen, Aarnoutse \& Van Leeuwe, 2010) and for foreign language learning (for a comprehensive review see Sparks \& Ganschow, 2001), one can anticipate that music can therefore enhance spelling and foreign language abilities, too. However, only few and fairly recent studies have linked musical abilities to spelling performance and foreign language acquisition.

Hille, Gust, Bitz and Kammer (2011) suggested that good spelling is correlated to playing musical instruments. The authors have shown that boys playing an instrument had better spelling performance than those who did not play an instrument, and the percentage of boys playing an instrument was higher among good spellers compared with poor spellers. Standley and Hughes (1997) and Register (2001) have shown that children receiving music instruction made greater gains in writing skills and print awareness.

The first rigorous study to demonstrate that musical abilities are correlated to foreign language acquisition skills was conducted by Slevc and Miyake (2006). They found that musical subjects who demonstrate good analysis, discrimination, and memorization ability can perceive and produce L2 sounds better than their non-musical peers. Subsequent studies confirmed that musical abilities were linked to foreign language pronunciation (Milovanov, Huotilainen, Välimäki, Esquef \& Tervaniemi, 2008), and to pronunciation but not to phonemic discrimination of foreign language words (Milovanov, Pietilä, Tervaniemi \& Esquef, 2010).

The aim of the study presented here was to assess to what degree one of the musical ability components, namely pitch discrimination ability, can be a good predictor of native and foreign language spelling performance.

\section{Method}

\section{Participants}

One hundred and seventy three Romanian-speaking students aged 9-11 (3rd and 4 th grade) were tested for the ability to discriminate the pitch of sounds. The students were all registered at the same urban elementary school. At the date of testing, all students had taken one class per week of music education theory for 
at least 10 months. Their teachers declared that it was expected of them to be able to identify and write basic musical notes on musical staffs.

The children were divided into two musical ability groups based on a pitch discrimination test (described below). A total of 27 students (10 males, 17 females) qualified for the N/M group and 24 students (13 males, 11 females) qualified for the $M$ group. The age of musical students (9.08-11.50 years, $M=10.33, S D=0.68$ ), and non-musical students $(9.58-11.25, M=10.23, S D=0.52)$ was not significantly different $(t=[49]=0.581, \mathrm{p}>0.05)$.

A total of 11 out of 24 musical students (45.83\%) declared having studied a musical instrument for at least one year, while none $(0 \%)$ of the non-musical students had studied a musical instrument. None of the students selected for testing had any reported auditory impairments, as declared by their parents.

\section{Procedures}

The students were tested in groups of 20-28, by classes, during their music class. Sound pitch discrimination activities were an integral part of their music curriculum, and they were told that they would have a special music lesson. During the test, students were required to mark, on a special music sheet using dots, whether the sounds played on a keyboard by a professional keyboard player went up or down. The music sheet used for testing had 24 short staffs. The test's rules of notation did not follow the general rules of music notation. The lowest played sound (C) was to be written on the first line, and the highest played sound $(G)$ was to be written on the fifth line. The spaces between the lines were not used. Neither duration nor any other music notation characteristics were taken into consideration.

Before the test was administered, students received instruction regarding the testing procedures and the sound notation to be used. They were also given the opportunity to practice 8 groups of 5 sounds with the test administrator (using 8 out of the 24 short staffs from the test paper). Each group of sounds was played twice, 10 seconds apart. Using an overhead projector, the test administrator showed the students the correct notation of the groups of sounds after each practice drill.

For the testing part, a total of 80 sounds were played (16 groups of 5 sounds each, using the remaining 16 staffs from the test paper). The groups of sounds were played twice, 10 seconds apart. The sounds within each group of 5 sounds were played 1 second apart. One point was assigned for every sound identified correctly, so students could earn points ranging from 0 to 80 . At the end of the test, 167 out of 173 students produced measurable answers.

The students' scores ranged from 1 to $78(M=33.65, S D=16.24)$. The students with scores of fewer than 20 points were assigned to the low musical ability group, or non-musical group (N/M), while students with scores higher than 50 points were assigned to the high musical ability group, or musical group (M). 
Table 1. Descriptive statistics representing percentage of errors

\begin{tabular}{lccccc}
\hline & & \multicolumn{2}{c}{$\begin{array}{c}\text { Musical } \\
(\mathbf{n}=\mathbf{2 4})\end{array}$} & \multicolumn{2}{c}{$\begin{array}{c}\text { Non-musical } \\
(\mathbf{n}=\mathbf{2 7})\end{array}$} \\
\cline { 3 - 6 } & & $\mathrm{M}$ & $\mathrm{SD}$ & $\mathrm{M}$ & $\mathrm{SD}$ \\
\hline \multirow{2}{*}{ 3rd grade } & Native & 1.16 & 1.48 & 3.68 & 4.05 \\
& Foreign & 4.34 & 3.35 & 13.33 & 8.22 \\
4th grade & Native & 0.13 & 0.25 & 1.02 & 1.09 \\
& Foreign & 3.19 & 1.64 & 11.61 & 7.54 \\
\hline
\end{tabular}

Spelling performance was assessed using dictation, since Romanian has a highly phonemic orthography. Dictation activities are a common practice in teaching native Romanian children how to spell correctly and students are used to it from 1st grade. The spelling test location was an isolated classroom within the elementary school. A total of 7 sentences using familiar Romanian words and 7 sentences in a foreign (fictional) language were dictated to the students, who were required to write them down correctly. The fictional words were created so they would not resemble any known word in Romanian or in any other foreign language the subjects might have been exposed to. The Romanian sentences had a total of 179 phonemes, and the foreign language sentences had a total of 94 phonemes. Each sentence was dictated twice, 10 seconds apart. Subjects were tested in groups of 6-8, of mixed composition ( $M$ and N/M), and were all seated at an equal distance from the sound source. All subjects were tested on a Wednesday and on a Thursday, between 9:00 and 11:00 a.m.

\section{Results}

Performance for the native and foreign language tests was computed as the percentage of errors. Descriptive statistics for these two dependent variables are presented in Table 1 . The two variables were positively correlated, Pearson's $r(51)=0.66, p<0.01$.

A 2(musical ability) $\times 2$ (grade) multivariate analysis of variance (MANOVA), with percent errors for native and foreign tests as dependent variables, was used to compare the spelling performance of the musical and non-musical groups on the native and foreign language tests.

Performance in the native language spelling test was influenced by musical ability $F(1,47)=6.44, p<0.015, \eta_{p}^{2}=0.120$ (musical children had significantly fewer errors than non-musical children; see Table 1 ) and grade $F(1,47)=7.54, p<0.009$, $\eta_{p}^{2}=0.138$ (4th grade children had better performance compared to 3 rd graders; 
see Table 1). No interaction effect was found between grade and musical ability $F(1,47)=1.49, p=0.228, \eta_{p}^{2}=0.031$.

Mann-Whitney's U Test results showed that no difference in spelling performance ( $p>0.05$, two-tailed test) could be found between musical 3rd graders $(M=1.16, S D=1.48, n=12)$ and non-musical 4th graders $(M=1.02, S D=1.09$, $n=12$ ) in the native language condition, indicating that the phonological abilities of musical students allow them to outperform their non-musical peers by about one year's worth of school academic effort.

Foreign language performance showed a main effect of musical ability, $F(1,47)=26.09, p<0.001, \eta_{p}^{2}=0.357$, again indicating better performance in musical versus non-musical children (see Table 1). No effect was found for grade $(F<1, \mathrm{~ns})$, indicating that the awareness of phonemes in foreign language words was not influenced by the grade of the students. No interaction effect was found between grade and musical skills $(F<1, \mathrm{~ns})$.

Overall, the non-musical group made 3.89 times more errors in the native language test, and 3.34 times more errors in the foreign language test, compared with the musical group.

\section{Discussion}

The results indicate that pitch discrimination ability might be a good predictor of spelling performance in both native and foreign languages. To the best of my knowledge, this is the first study to connect pitch discrimination with foreign language spelling ability and one of few studies that link music to spelling. The data support previous findings of Slevc and Miyake (2006) connecting music to foreign language discrimination, but contradict the results of Milovanov, Pietilä, Tervaniemi and Esquef (2010), who did not find a link between phonemic discrimination ability in a foreign language and musical aptitude.

The positive causal relationship between the two variables suggests that better native language abilities also mean better foreign language abilities, and they are probably linked to individual verbal abilities. The data are consistent with the findings of Andreou and Karapetsas (2004), who found that verbal ability in the native language can be generalized to a foreign language.

Interestingly, the results also provide a measurable time frame for the impact that musical skills have on spelling performance in the native language: since the difference in level of performance of musical 3rd graders and non-musical 4th graders was statistically insignificant, it can be inferred that musical students have the potential to be one year ahead of their non-musical peers.

The analysis shows that understanding of phonemes uttered in a foreign language can be significantly improved when subjects have high pitch discrimination ability, which creates favorable premises for second language acquisition. Since the data indicate that more musical students (45.83\%) studied a musical 
instrument than their non-musical peers $(0 \%)$, and since the results also show that musical ability is not influenced by the grade of students, it can be deduced that phonological awareness performance and second language acquisition skills might be improved by studying a musical instrument. The correlation between spelling and musical instrument study is consistent with the findings of Hille et al. (2011) presented above.

As expected, grade played a significant role in the performance of students in the native language test, indicating that students improve their spelling from one academic year to another, due to practice during school activities. However, grade did not influence the foreign language phonological awareness, indicating that it is not age but musical ability that makes a difference in foreign language acquisition performance.

The results' generalization might be limited by the fact that the subjects' native language orthography was highly phonemic, unlike English, for example. Similar investigations might be needed to address this issue.

In sum, the study provides additional evidence, gained by applying a different methodology, that musical ability is correlated with foreign language acquisition. It also offers what is probably the first clear evidence that pitch discrimination can be a good predictor of spelling performance in native and foreign languages.

\section{Acknowledgements}

The author would like to thank the students, parents, teachers and school administrators for voluntarily participating in this study. He would also like to thank Ioana Tincas for statistical analysis assistance and helpful comments and Markus Rheindorf for proofreading an earlier draft of this paper.

This work was made possible by the financial support of the Sectoral Operational Programme for Human Resources Development 2007-2013, co-financed by the European Social Fund, under the project number POSDRU/107/1.5/S/76841 entitled "Modern Doctoral Studies: Internationalization and Interdisciplinarity."

\section{References}

Andreou, G. \& Karapetsas, A. (2004). Verbal abilities in low and highly proficient bilinguals. Fournal of Psycholinguistics Research, 33(5), 357-364.

Ball, E.W. \& Blachman, B. (1991). Does phoneme awareness training in kindergarten make a difference in early word recognition and developmental spelling? Reading Research Quarterly, 26, 49-66.

Bengtsson, S.L., Nagy, Z., Skare, S., Forsman, L., Forssberg, H., \& Ullén, F. (2005). Extensive piano practicing has regionally specific effects on white matter development. Nature Neuroscience, 8, 1148-1150. 
Ehri, L.C., Nunes, S.R., Willows, D.M., Schuster, B.V., Yaghoub-Zadeh, Z., \& Shanahan, T. (2001). Phonemic awareness instruction helps children learn to read: Evidence from the National Reading Panel's meta-analysis. Reading Research Quarterly, 36, 250-287.

Flohr, J.W., Miller, D.C., \& deBeus, R. (2000) EEG studies with young children. Music Educators fournal, 87(2), 28-32.

Forgeard, M., Schlaug, G., Norton, A., Rosam, C.F., Iyengar, U., \& Winner E. (2008). The relation between music and phonological processing in normal reading children and children with dyslexia. Music Perception, 25, 383-390.

Gromko, J. (2005). The Effect of Music Instruction on Phonemic Awareness in Beginning Readers. Fournal of Research in Music Education, 53(3), 199-209.

Hille, K., Gust, K., Bitz, U., \& Kammer, T. (2011). Associations between music education, intelligence, and spelling ability in elementary school. Advances in Cognitive Psychology, 7, 1-6.

Lamb, S.J. \& Gregory, A.H. (1993) The relationship between music and reading in beginning readers, Educational Psychology: An International fournal of Experimental Educational Psychology, 31(1), 19-27.

Magne, C., Schön, D., \& Besson, M. (2006). Musician Children Detect Pitch Violations in Both Music and Language Better than Nonmusician Children: Behavioral and Electrophysiological Approaches. Journal of Cognitive Neuroscience, 18(2), 199-211.

Milovanov, R., Huotilainen, M., Välimäki, V., Esquef, P.A.A., \& Tervaniemi, M. (2008). Musical aptitude and second language pronunciation skills in school-aged children: neural and behavioral evidence. Brain Research, 1194, 81-89.

Milovanov, R., Pietilä, P., Tervaniemi, M., \& Esquef, P. (2010). Foreign language pronunciation skills and musical aptitude: A study of Finnish adults with higher education. Learning and Individual Differences, 20, 56-60.

Moreno, S., \& Besson, M. (2006) Musical training and language-related brain electrical activity in children. Psychophysiology, 43, 287-291.

Moreno, S., Marques, C., Santos, A., Santos, M., Castro, S.L., \& Besson, M. (2009). Musical abilities in 8-year-old children: more evidence for brain plasticity. Cerebral Cortex, 19, 712-723.

Register, D. (2001). The effects of an early intervention music curriculum on prereading/writing. Fournal of Music Therapy, 38(3), 239-248.

Schlaug, G., Forgeard, M., Zhu, L., Norton, A., Norton, A., \& Winner, E. (2009). Training-induced neuroplasticity in young children. Annals of the New York Academy of Sciences, 1169, 205-208.

Slevc, L.R. \& Miyake, A. (2006). Individual differences in second language proficiency: Does musical ability matter? Psychological Science, 17(8), 675-681.

Sparks R., \& Ganschow, L. (2001). Aptitude for learning a foreign language. Annual Review of Applied Linguistics, 21, 90-111. 
Standley, J.M., \& Hughes, J.E. (1997). Evaluation of an early intervention music curriculum for enhancing prereading/writing skills. Music Therapy Perspectives, 15(2), 79-85.

Stuart, M. (1999). Getting ready for reading: early phoneme awareness and phonics teaching improves reading and spelling in inner-city second language learners. British fournal of Educational Psychology, 69, 587-605.

Verhagen, M.W., Aarnoutse, C.J., \& Van Leeuwe, J.F.J. (2010). Spelling and word recognition in grades 1 and 2: Relations to phonological awareness and naming speed in Dutch children. Applied Psycholinguistics, 31, 59-80. 